\title{
A LEITURA MUSICAL COMO RECURSO PARA O DESENVOLVIMENTO DE HABILIDADES MATEMÁTICAS DA BASE NACIONAL COMUM CURRICULAR
}

\section{MUSICAL READING AS RESOURCE FOR THE DEVELOPMENT OF MATHEMATICAL SKILLS OF THE NATIONAL COMMON CURRICULAR BASE}

\author{
Daniel do Nascimento Rodrigues ${ }^{1}$ \\ Universidade Estadual Vale do Acaraú - Uva \\ Daniel Brandão Menezes ${ }^{2}$ \\ Universidade Estadual Vale do Acaraú - Uva
}

\begin{abstract}
Resumo
Este trabalho apresenta uma pesquisa sobre a relação entre a leitura musical e a matemática onde analisa a utilização dessa leitura para o desenvolvimento de habilidades matemáticas do ensino fundamental. Em decorrência da aprovação de leis que dispõem sobre a obrigatoriedade do ensino de música nas escolas, da sistematização de habilidades por meio de documentos de caráter normativo e da estreita relação que a matemática tem com a música, esta ultima, por sua vez, caracterizando-se como um artifício didático, constituem a base e o ponto norteador deste trabalho. A pesquisa foi feita por meio de um estudo bibliográfico dos conceitos musicais, de habilidades da BNCC e de trabalhos científicos que relacionam a matemática com a música. $\mathrm{O}$ resultado mostra que muitos conceitos matemáticos são essenciais na leitura musical e que essa leitura interdisciplinar favorece o desenvolvimento de habilidades matemáticas. Dessa forma, ela possibilita a utilização da música como ferramenta para o ensino/aprendizagem. A leitura de partituras musicais, por ser considerada, de certa forma, uma leitura de números, se transforma na manipulação de contas matemáticas que contribuem para o desenvolvimento de habilidades matemáticas.
\end{abstract}

Palavras-chave: BNCC; Habilidades Matemáticas; Leitura Musical; Música.

\begin{abstract}
This work presents a research on the relation between musical reading and mathematics, analyzing the use of this reading for the development of mathematical abilities of elementary school. As a result of the approval of laws, which have the compulsory teaching of music in schools, the systematization of skills through normative documents and the strict relation that mathematics has with music, the latter in turn characterizing itself as a didactic artifice, constitute the base and the guiding point of this work. The research was done through a bibliographic study of musical concepts, skills and scientific works with their practical applications and conclusions. The result shows that many mathematical concepts are essential in musical reading that this interdisciplinary reading favors the development of mathematical abilities, thus enabling the use of music as a teaching / learning tool. Thus, the reading of
\end{abstract}

\footnotetext{
1 danielnascro@hotmail.com

2 brandaomenezes@ hotmail.com
} 
musical scores, being considered in a certain way a reading of numbers, is transformed in the manipulation of mathematical accounts that contribute to the development of mathematical abilities.

Keywords: BNCC; Mathematical Abilities; Musical Reading; Music.

\section{Introdução}

Em 2008, a lei 11.769/08 (BRASIL, 2008), que torna obrigatório o ensino de música nas escolas de educação básica, foi sancionada. A sua aprovação fundamenta-se no princípio de que a música contribui para uma melhor formação dos estudantes. Segundo a senadora Roseana Sarney "Estudos e pesquisas mostram que a aprendizagem musical contribui para o desenvolvimento cognitivo, psicomotor, emocional e afetivo e, principalmente, para a construção de valores pessoais e sociais de crianças e jovens" (SARNEY, 2006). D'Ambrósio (2009) reconhece a necessidade de uma reformulação no ensino para algo que esteja mais próximo da realidade dos estudantes. Diante de várias maneiras de incentivo escolar, a música ganha importância por despertar interesse e por sua presença constante na sociedade.

Desde muitos anos no Brasil, houve a necessidade de uma base curricular comum que servisse de referência para as instituições de ensino construírem o seu currículo. Tanto a constituição federal de 1988, a Lei de Diretrizes e Bases da Educação Nacional (BRASIL, 1996) e o Plano Nacional de educação (BRASIL, 2014) previam a construção desse documento. Porem, só em 2017, depois de várias discussões e algumas versões prévias, a Base Nacional Comum Curricular foi realmente consolidada. Este documento foi estabelecido para a educação infantil e ensino fundamental, previsão para o do ensino médio em breve, para ser um referencial curricular nacional que sintetiza um conjunto de conhecimentos essências aos estudantes, contudo, sem excluir as peculiaridades culturais locais.

Diante desse contexto, é possível utilizar a leitura musical como meio para desenvolver habilidades matemáticas listadas pela base nacional comum curricular do ensino fundamental? Segundo Bréscia (2003), o estudo de música favorece o desenvolvimento da memória, da imaginação, da concentração, atenção; Mas, de uma forma mais específica, o estudo dessa arte pode influenciar na aprendizagem da matemática? 
A leitura da partitura musical, considerada, de certa forma, uma leitura de números, se transforma na manipulação de contas matemáticas. Saber que a matemática é constantemente trabalhada na execução de uma partitura musical e que possibilita o desenvolvimento de habilidade matemáticas constitui um artifício para a aprendizagem interdisciplinar e inovadora. Uma análise de estruturas musicais utilizadas na prática permitirá identificar onde a matemática está presente e como essas habilidades são trabalhadas. Esse estudo se apoia em alguns documentos como a lei 11.769/08 (BRASIL, 2008) e a Base Nacional Comum Curricular - BNCC (BRASIL, 2017), de caráter normativo, que, ao poucos, estão se incorporando a vivencia escolar. É evidente, principalmente para músicos, que uma partitura musical é representada por símbolos de caráter numérico e que, ao fazer a leitura dessa partitura, o individuo executa naturalmente contas matemáticas. Esses cálculos estimulam o cognitivo matemático em diversos aspectos tais como os mencionados no estudo de Rocha e Boggio (2013). A metodologia desta pesquisa acontece por meio do estudo bibliográfico dos conceitos musicais, das habilidades da BNCC e de trabalhos científicos com suas aplicações práticas e conclusões.

\section{Conceitos Musicais}

Adiante, serão explicados conceitos básicos da música e tópicos importantes que serão mencionados mais a frente para que o leitor possa compreendê-los e relacioná-los matematicamente.

\section{Pauta e tempo}

"Escreve-se a música sobre 5 linhas e 4 espaços horizontais paralelas e equidistantes. A estas linhas e espaços dá-se o nome de PAUTA ou PENTAGRAMA.” (NOBRE, 2008, p.2). A definição de Nobre (2008) é de uma estrutura universal, a linguagem musical é compreendida mundialmente. O pentagrama recebe as notas musicais que são colocadas em cima das linhas e entre os espações horizontais paralelos.

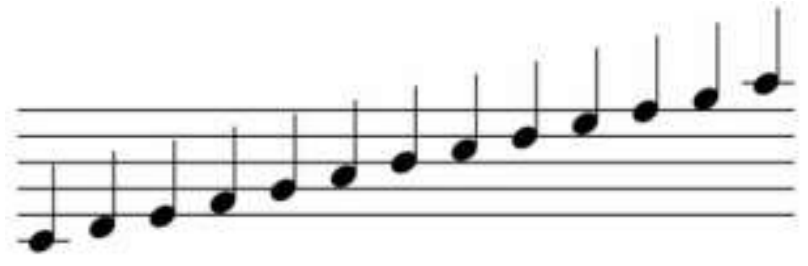


Fonte: Blog - Escola Virtual de Música

“Em música existem sons longos e sons breves. Há também momentos quando se interrompe a emissão do som: os silêncios" (MED, 1996, p.20). O tempo de uma nota é a duração que ouvimos o seu som ecoando. Para fim didático, representamos 1 tempo como sendo a duração do som por 1 segundo, mas 1 tempo varia de acordo com o andamento da música podendo ser mais longo ou mais curto. A interrupção do som na música mencionado por Med (1996) é chamado de pausa. O tempo das pausas, assim como o tempo das notas, é indicado conforme o formato da figura. Cada duração de uma nota tem sua respectiva pausa.

\begin{tabular}{|c|c|c|c|}
\hline Figura & Pausa & Tempo & Nome \\
\hline o & $=$ & 4 & SEMIBREVE \\
\hline & - & 2 & MINIMA \\
\hline & ? & 1 & SEMINIMA \\
\hline d & 7 & $1 / 2$ & COLCHEIA \\
\hline A & 7 & $1 / 4$ & SEMICOLCHEIA \\
\hline A & ; & $1 / 8$ & FUSA \\
\hline
\end{tabular}

Fonte: Blog - Magia da Música

As figuras de notas musicais e das pausas estão representadas juntamente com seus respectivos tempos e nomes. Para o caso da nota semibreve, figura semelhante a uma elipse, existe um símbolo de pausa correspondente ao tempo da nota, 4 tempos. Isso significa que, quando aparecem semibreves em uma partitura, o indivíduo deve emitir o som por 4 tempos (aproximadamente 4 segundos); da mesma forma, o indivíduo deve permanecer em silêncio por 4 tempos caso apareça o respectivo símbolo de pausa.

\section{Ligadura e tempo de aumento}

A Ligadura é uma linha curvada que une duas ou mais notas. Na ilustração abaixo, as duas semínimas (nota de 1 tempo) fazem o papel de uma mínima (nota de dois tempos). O Ponto de Aumento, como o nome já diz, é um ponto colocado à direita da nota ou pausa para aumentar o seu valor. Ele acrescenta a metade do valor da nota ou pausa. 


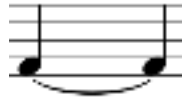

Fonte: autor

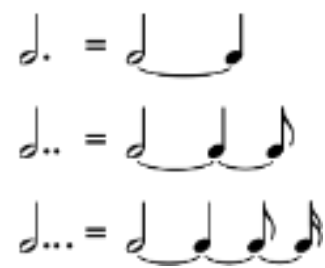

Fonte: https://pt.wikipedia.org/wiki/Ponto_(m\%C3\%BAsica)

\section{Andamento}

Para Med (1996), o termo de andamento na música indica a velocidade atribuída a um trecho musical. A música pode ser executada numa pulsação mais rápida, mais lenta ou em andamento moderado, conforme o critério de quem toca. Existe uma representação numérica que define o andamento da música numa partitura musical, ela é importante para que músicos que nunca ouviram uma determinada melodia possam tocá-la respeitando a velocidade adequada. O símbolo do andamento é colocado no topo da partitura representada por uma nota musical igualada a um número inteiro da seguinte forma $(\cdot=60)$. O tipo de nota escolhido para representar esse andamento é apenas ilustrativo já o número colocado à direita indica a quantidade de notas com tempos constantes que são tocadas em 1 minuto. Por exemplo, o andamento $(\cdot=132)$ indica uma música de velocidade rápida numa pulsação de 132 notas constantes tocadas em 60 segundos. $\mathrm{O}$ andamento $(\bullet \mathbf{4 8})$ indica uma música de velocidade lenta numa pulsação de 48 notas constantes tocadas em 60 segundos.

\section{Estruturas Musicais e a Matemática}

A partir do que foi exposto no capítulo anterior, será analisado matematicamente os tópicos musicais usados com maior frequência quando se executa uma partitura musical. O primeiro tópico matemático a ser abordado na música, um dos utilizados com maior frequência por quem lê partitura, é a utilização da aritmética. Os diversos elementos da pauta são, na maioria, números matemáticos envolvidos em operações. Esses elementos se relacionam dando sentido a música e são compreendidos por meio das operações de adição, subtração, multiplicação e divisão. "A música é um exercício de aritmética secreta e aquele que a ela se consagra ignora que manipula números". (LEIBNIZ). 


\section{Aritmética: Ligadura e Ponto de Aumento}

Iniciando com as ligaduras. O interesse é na ligadura inscrita em notas que estejam na mesma linha ou que estejam no mesmo espaço entre duas linhas da pauta. Desta forma, esse símbolo de ligação de notas ganha o papel de adição de tempos.

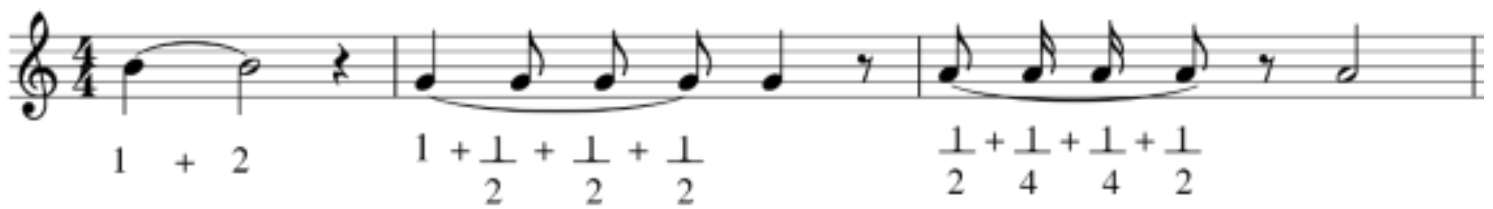

Fonte: autor

Os pontos de aumento simples e duplos também representam uma soma.

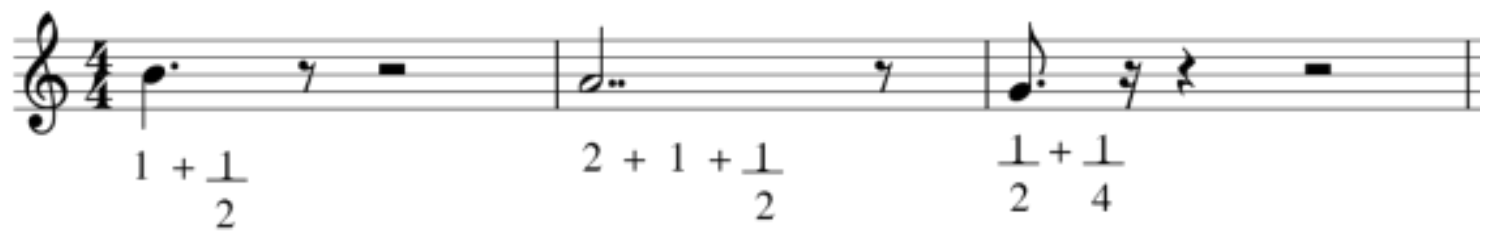

Fonte: autor

Esses elementos são bem evidentes na música "Samba de Uma Nota Só" de Tom Jobim (1960) onde soma de tempos de notas aparecem no primeiro pentagrama. Percebese que o resultado das somas são 1, 2 e 1 tempos respectivamente então, por que não colocar a nota semínima (nota de 1 tempo) e mínima (nota de 2 tempo) no lugar das outras para suprimir a necessidade de cálculos? Essa questão é explicada pela regra de compasso que define a quantidade de tempo em cada compasso. Caso fosse colocado a nota de 2 tempos no segundo compasso, o tempo total excederia 1,5 tempo visto que são definidos apenas 4 tempos por compasso. Dessa forma, é necessária a utilização dessa distribuição de notas acima acarretando, assim, a utilização constante de somas por meio da ligadura e do ponto de aumento.

\section{SAMBA DE UMA NOTA SÓ}

Bossa Nova

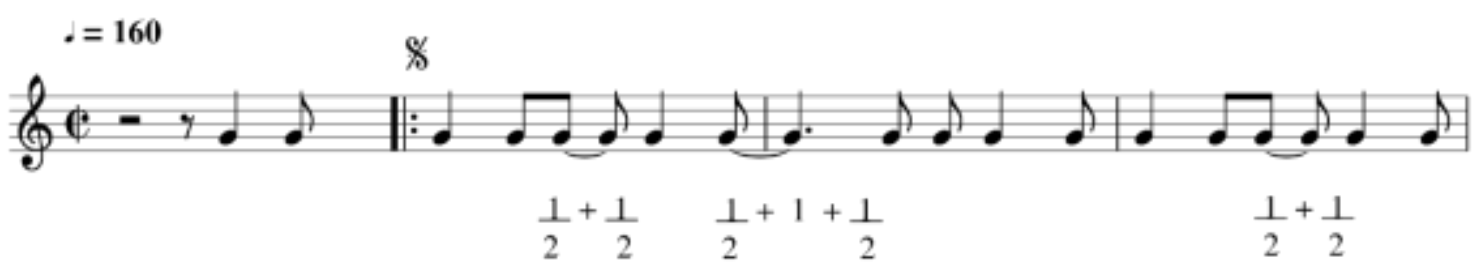

Fonte: autor 


\section{Razão e Proporção: andamento}

A noção de proporcionalidade na música acontece no conceito de andamento. $\mathrm{Na}$ variação de uma grandeza outra grandeza também varia aumentando ou diminuindo proporcionalmente. Na música do Tom Jobim (1960) mencionada acima, o andamento é considerado rápido na definição de 160 notas regulares tocadas em 1 minuto. Caso o número de notas regulares tocadas em 1 minuto decresça implicará a diminuição do andamento da música assim como se o número de notas regulares tocadas em 1 minuto aumenta consequentemente o andamento da música aumentará.

$$
\frac{160}{60} \approx 2,7 \quad \downarrow \frac{130}{60} \approx 2,2 \downarrow \mathbb{\downarrow} \frac{175}{60} \approx 2,8 \boldsymbol{\prod}
$$

Quadro 2 - Andamento

\begin{tabular}{|c|c|}
\hline \multicolumn{2}{|c|}{$\cdot \mathbf{X}$} \\
\hline Número $\mathbf{X}$ & Andamento \\
\hline Cresce & Aumenta \\
\hline Decresce & Diminui \\
\hline
\end{tabular}

Fonte: Autor

Essa representação de proporcionalidade acima está esquematizada de forma didática para que o leitor possa entender o comportamento da proporcionalidade no conceito musical de andamento. Na execução de uma partitura, o músico não irá calcular, a rigor, o resultado dessa divisão, mas, para que ele interprete o andamento da música, é imprescindível a noção de proporcionalidade.

\section{Habilidades matemáticas da base nacional comum curricular relacionadas com a leitura musical}

Abaixo, está uma análise a respeito das habilidades desenvolvidas através do estudo de números inteiros, fracionários e de proporcionalidade, termos que são encontrados na leitura musical. Contudo, a prática dessa leitura não estimula por completo algumas habilidades, pois algumas delas são amplas diante da limitação da música; mas não diminui a importância da música em estimular o cognitivo matemático.

A unidade temática "Números" da BNCC se faz presente no ensino fundamental do $1^{\circ}$ ao $9^{\circ}$ ano com abordagens e noções de acrescentar, juntar, completar, comparar, separar, retirar, frações, medições, dobro, metade, parte de um todo, soma, subtração, 
multiplicação, divisão inseridos numa abordagem mental ou de escrita. Da mesma forma que estas noções se fazem presentes na BNCC, também se fazem presentes na música. O ponto de aumento e a ligadura na partitura musical possibilitam a assimilação de algumas noções, tais como “juntar” e “acrescentar”, a concepção de compasso permite o manuseio de números fracionários. Percebe-se, dessa forma, o grande potencial da música para o desenvolvimento cognitivo matemático; além dos cálculos mentais serem algo essencial na música devido à necessidade da leitura instantânea da partitura.

Apesar desta nítida ligação, a leitura musical pode não trabalhar por completo algumas habilidades. Uma habilidade como exemplo é a (EF06MA03) "Resolver $e$ elaborar problemas que envolvam cálculos (mentais ou escritos, exatos ou aproximados) com números naturais, por meio de estratégias variadas, com compreensão dos processos neles envolvidos com e sem uso de calculadora". A colocação da resolução de problemas por meio de estratégias variadas se restringirá apenas no âmbito musical além do não uso da calculadora. O conceito de problemas pode ser entendido nas diversas necessidades da leitura de símbolos musicais

Algumas habilidades podem ser mais trabalhadas e outras nem tanto. $\mathrm{Na}$ habilidade (EF08MA13): "Resolver e elaborar problemas que envolvam grandezas diretamente ou inversamente proporcionais, por meio de estratégias variadas." A leitura musical pode contribuir para o desenvolvimento no que se refere a resolver problemas que envolvam grandezas diretamente proporcionais, por meio de estratégias variadas. Já na habilidade (EF05MA19): "Resolver e elaborar problemas envolvendo medidas das grandezas comprimento, área, massa, tempo, temperatura e capacidade, recorrendo a transformações entre as unidades mais usuais em contextos socioculturais." A leitura musical se restringiria a resolução de situações problemas envolvendo apenas medidas de tempo e ainda de forma limitada, visto que a música utiliza mais contagens referentes aos segundos. Neste caso, a leitura musical contribuiria numa pequena fração para o desenvolvimento dessa habilidade. O que pode ser percebido nesta observação é que os conceitos matemáticos da leitura musical integram, na sua maior parte, parcialmente algumas habilidades da BNCC

\section{Abordagens metodológicas matemática em uma integração musical}


Nunes (2012), em seu trabalho de conclusão de curso intitulado: "Relação entre matemática e música: uma proposta para o ensino de frações equivalentes e proporções no sétimo ano" apresenta uma abordagem didática para o ensino de frações e proporções num contexto musical e compara os resultados com uma abordagem tradicional do mesmo conteúdo. A intenção é trazer uma proposta alternativa pedagógica de forma musical e identificar possíveis benefícios que essa relação pode propiciar para o ensino de frações equivalentes e ensino de proporções. Das duas turmas acompanhadas por Nunes (2012), foram desenvolvidas atividades em uma turma com a utilização de metodologia de ensino tradicional (turma A) e em uma segunda turma foram desenvolvidas atividades com metodologia diferenciada por meio de instrumentos musicais de cordas e leitura de tablaturas (uma leitura musical especifica destinada principalmente para instrumentos de cordas) (turma B). Na turma B, as aulas aconteceram inicialmente de modo que os alunos pudessem interagir através de músicas e através de vídeos sobre a relação da matemática com a música para compreenderem a proposta da aplicação. Num segundo momentos, os alunos aprendiam o básico da leitura musical juntamente com os conceitos matemáticos necessários a essa leitura. Num terceiro momento, os alunos colocavam em prática a matemática abordada por meio de instrumentos musicais e leitura de partitura de modo que, com a mediação do professor, a relação matemática ficava compreendida.

Com a realização das atividades foi possível, através de pré-testes e pós-testes, fazer uma sistematização dos resultados. De posse dos resultados, Nunes (2012) constatou uma melhoria nos resultados em ambas as turmas, mas com uma observação no fato de "... que os alunos que realizaram as atividades relacionadas à música se envolveram, participaram, dedicaram-se de forma surpreendente..." (NUNES, 2012. P. $40)$.

\section{Considerações finais}

O presente trabalho permitiu analisar a possibilidade do desenvolvimento de habilidades matemáticas listada pela Base Nacional Comum Curricular (2017) do ensino fundamental por meio da leitura de partituras musicais para que, diante dessa relação, essa leitura contribua no processo de aprendizagem matemática. Além disso, buscou-se 
evidenciar que mudanças na sociedade acarretam a necessidade de mudanças pedagógicas.

De uma forma geral, pode-se concluir que a leitura de partitura musical permite a realização de cálculos matemáticos mentais e mais elaborados tais como cálculos de somas, subtrações, multiplicação, divisão, frações e proporção possibilitando, dessa forma, serem um meio didático motivador para o ensino da matemática. Diante dos resultados positivos da análise das pesquisas de aplicações em sala de aula sobre os temos abordados neste trabalho e das várias habilidades matemáticas encontradas na Base Nacional Comum Curricular (2017) que se relacionam, mesmo que parcialmente, com o estudo de música, os objetivos desta pesquisa foram alcançados com êxito evidenciando, assim, que a leitura de partituras pode contribuir para aprendizagem de habilidades matemáticas.

Todavia, as discussões nesse âmbito ainda são poucas. Diante da obrigatoriedade recente do ensino de músicas nas escolas de educação básica, os estudos voltados para essa relação cresceram, porém necessitam de mais. A matemática pode ser encontrada na música em diversas possibilidades. Este trabalho se restringe à leitura musical. Pesquisas posteriores podem identificar outras habilidades matemáticas da Base Nacional Comum Curricular (2017) trabalhadas através da música, independente de ser ou não por meio da leitura de partitura.

Saber que a matemática é trabalhada constantemente na execução de uma partitura musical e que possibilita o desenvolvimento de habilidade matemáticas constitui, esse fato, um artifício para uma aprendizagem significativa. Essas relações podem ser aproveitadas como metodologias de ensino e incentivar o gosto pela matemática. Neste sentido, este trabalho conclui favoravelmente a possibilidade do desenvolvimento de habilidades matemáticas listadas pela BNCC (2017) por meio da leitura de partituras musicais e, além disso, surge como um aporte teórico para que docentes e discentes possam utilizar como aprimoramento de suas sessões didáticas relacionadas à matemática e a música.

\section{Referências}

BASTOS, N. Figuras Musicais. MAGIA DA MÚSICA. 2015. Disponível em: $<$ https://magiadamusica.webnode.pt/figuras-musicais/> Acesso em: 06/2018. 
BRASIL, Lei 11.769, de 18 de agosto de 2008a. Brasília, 2008. Disponível em: <http://www.planalto.gov.br/ccivil_03/_ato2007-2010/2008/lei/111769.htm>. Acesso em 10 jun. 2018.

BRASIL. Lei ${ }^{\circ} 13.005$, de 25 de junho de 2014. Aprova o Plano Nacional de Educação - PNE e dá outras providências. Brasília, DF, 25 de junho de 2014. Disponível em: http://www.planalto.gov.br/ccivil_03/_Ato2011-2014/Lei/L13005.htm. Acesso em: jun 2018.

BRASIL. Ministério da Educação. 2018. disponível em: Ministério da Educação: http://portal.mec.gov.br/component/tags/tag/37551. Acesso em 23 de Julho de 2018.

BRÉSCIA, V. L. Educação Musical: bases psicológicas e ação preventiva. São Paulo, 2003: Átomo.

CAMPOS, R. Como ler partituras, Claves musicais. Escola Virtual de Música. 03/08/2017.Disponível em: <https://www.escolavirtualdemusica.com.br/como-lerpartituras-claves-musicais/> Acesso em: 06/2018.

MED, B. Teoria da música, 4ª edição, Editora Musimed, Brasília - DF - 1996.

NUNES, R. M. Relação entre matemática e música: uma proposta para o ensino de frações equivalentes e proporções no sétimo ano. Canoas, 2012.

NOBRE, J. Apostila de Teoria Musical, Projeto Fortalecimento Musical, Secretaria Estadual da Cultura - SECULT, Ceará - 2006.

ROCHA, V. C., \& BOGGIO, P. S. A música por uma óptica neurocientífica. 2013. p. 9.

SENADO FEDERAL. Projeto Lei do Senado, $n^{\circ}$ 330/2006, de 15 de dezembro de 2006b. Brasília 2006. Disponível em. <www.senado.leg.br/atividade/rotinas/materia/getDocumento.asp?t=9079> Acesso em jun. 2018. 